\title{
UJI AKURASI PRODUK ESTIMASI CURAH HUJAN SATELIT GPM IMERG DI SURABAYA, INDONESIA
}

\author{
Accuracy Test of GPM IMERG Rainfall Estimation Product over Surabaya, \\ Indonesia
}

\author{
Mukhamad Adib Azka ${ }^{1) *}$, Prabu Aditya Sugianto1), Andreas Kurniawan Silitonga1), Imma Redha \\ Nugrahenil)
}

1) Sekolah Tinggi Meteorologi Klimatologi dan Geofisika, Jalan Perhubungan I No. 5 Kel. Pondok Betung, Kec. Pondok Aren, Tangerang Selatan, Banten.

*E-mail: mukhamadadibazka9@gmail.com

\begin{abstract}
Intisari
Curah hujan merupakan parameter meteorologi yang sangat berpengaruh dalam kehidupan. Saat ini, pengamatan secara in situ sangat kurang representatif untuk digunakan sebagai analisis karena jangkauannya yang sangat sempit sehingga memerlukan instrumen pendukung seperti satelit agar dapat memberikan gambaran yang lebih baik terkait distribusi hujan. Namun, data satelit juga belum tentu sepenuhnya benar karena resolusi dan kondisi dari setiap wilayah berbeda. Penelitian ini bertujuan untuk mendapatkan nilai akurasi, bias, korelasi, root mean square error (RMSE), dan mean absolute error (MAE) data estimasi curah hujan GPM IMERG dengan data curah hujan pengamatan langsung. Penelitian ini dilakukkan di Surabaya dengan menggunakan data estimasi curah hujan GPM IMERG dan data curah hujan pengamatan langsung dari Stasiun Meteorologi Kelas I Juanda Surabaya selama tahun 2017 mewakili musim hujan, musim kemarau, dan periode transisi. Hasil penelitian menunjukkan bahwa data curah hujan produk GPM IMERG memiliki korelasi yang sangat baik untuk memperkirakan akumulasi curah hujan bulanan. Sedangkan, untuk akumulasi harian, memiliki korelasi yang sangat rendah. Sementara itu untuk akumulasi sepuluh harian, data curah hujan produk satelit GPM IMERG memiliki korelasi yang baik terutama di periode musim hujan dan musim kemarau, akan tetapi memiliki korelasi yang rendah selama periode transisi dari musim hujan ke musim kemarau atau sebaliknya. Pada umumnya, produk ini sangat bagus dalam menentukan ada atau tidaknya hujan, tetapi performanya sangat rendah dalam menentukan besarnya intensitas curah hujan.
\end{abstract}

Kata Kunci : Curah Hujan, GPM IMERG, Akurasi.

\begin{abstract}
Rainfall is one of the most influential meteorological parameter in life. At present, in situ observation is less representative in its use as an analysis tool because of its very narrow analytical range which necessitates the use of supporting instruments such as satellites. These instruments would provide a better picture with regards to rain distribution. However, satellite data is not necessarily correct entirely due to different resolutions and conditions of each region. This study aims to obtain the GPM IMERG Final Precipitation estimation data accuracy, bias, correlation, root mean square error (RMSE), and mean absolute error (MAE) values, by using direct observation rainfall data. This research was conducted in Surabaya by using GPM IMERG Final Precipitation rainfall estimation data and direct observation rainfall data from The Class I Meteorological Station in Juanda, Surabaya. This research was carried out in 2017 and includes the rainy season, dry season and the transition period of that year. The results showed that the GPM IMERG product rainfall data had a very good correlation to estimate the accumulation of monthly rainfall. Whereas, for daily accumulation, it has a very low correlation. Meanwhile for the accumulation of ten daily, rainfall data for GPM IMERG satellite products has a good correlation, especially in the rainy season and dry season, but has a low correlation during the transition period from the rainy season to the dry season or vice versa. In general, this product is very good in determining the presence or absence of rain, but its performance is very low in determining the amount of rainfall intensity.
\end{abstract}

Keywords : Rainfall, GPM IMERG, Accuracy. 


\section{PENDAHULUAN}

Curah hujan merupakan parameter meteorologi yang sangat berpengaruh dalam kehidupan. Indonesia merupakan negara beriklim tropis yang berada di equator sehingga mendapatkan penyinaran matahari yang maksimal. Oleh karena itu, Indonesia memiliki penguapan dan intensitas curah hujan yang cukup tinggi. Saat ini, pengamatan secara insitu sangat kurang representatif untuk digunakan sebagai prakiraan karena jangkauannya yang sangat sempit sehingga memerlukan instrumen pendukung yang dapat memberikan gambaran yang lebih baik terkait distribusi hujan dan sebagai penunjang akurasi prakiraan, salah satunya adalah satelit (Sharifi, 2016). Namun, data satelit juga belum tentu sepenuhnya benar karena resolusi dan kondisi dari setiap wilayah berbeda. Salah satu produk estimasi curah hujan yang dapat kita manfaatkan yaitu data estimasi curah hujan satelit GPM (Global Precipitation Measurement) IMERG Final Precipitation.

Global Precipitation Measurement (GPM) diluncurkan pada 27 Februari 2014. Misi internasional ini dipimpin oleh National Aeronautics and Space Administration (NASA) dan Japan Aerospace and Exploration Agency (JAXA), sebagai penerus Tropical Rainfall Measuring Mission (TRMM), untuk melanjutkan dan meningkatkan kualitas observasi curah hujan dan salju berbasis satelit salju dalam skala global (Tapiador et al., 2012; Hou et al., 2014; Yong et al., 2015). IMERG Final Precipitation didapat setelah analisis hujan bulanan diterima dan diambil kemudian diperhitungkan (O, 2017). GPM terdiri dari instrumen utama yaitu GMI (GPM Microwave Imager) dan DPR (Dual Precipitation Radar) dan konstelasi satelit mitra untuk mengumpulkan informasi dari banyak platform satelit Passive Microwave (PMW) dan Infrared (IR) yang tersedia. Pendekatan PMW-IR yang digabung tersebut dapat saling meningkatkan manfaat masing-masing dari estimasi curah hujan PMW atau IR yang berbasis satelit, yaitu perkiraan satelit IR dapat disesuaikan dengan keakuratan data PMW yang lebih besar dan sebaliknya, perkiraan satelit PMW dapat diinterpolasi sepanjang pergerakan awan yang diperoleh dengan nilai sampling yang tinggi dari data IR (Kidd et al., 2003; Kidd \& Huffman, 2011; Kidd \& Levizzani, 2011). Setelah data observasi diterima dari platform PMW dan IR, data tersebut digabungkan menjadi bidang grid setengah jam Integrated Multi-satellite Retrievals for GPM (IMERG) (Huffman et al., 2015).Berdasarkan analisis awal selama pengujian beta, IMERG lebih halus dari 3B43 di atas lautan dan di garis lintang yang lebih tinggi.

Belum banyak pengujian mengenai produk estimasi curah hujan data Integrated Multi-satellite Retrievals for GPM (IMERG) Final Precipitation di
Indonesia. Sharifi (2016) menyatakan bahwa IMERG menghasilkan hasil yang lebih baik untuk mendeteksi curah hujan peristiwa atas dasar Probability of Detection (POD), Critical Success Index (CSI) dan False Alarm Ratio (FAR) di daerah-daerah dengan curah hujan stratiform dan orografis, seperti Teheran dan Kermanshah (Iran), dibandingkan dengan set data satelit/model lainnya. Khususnya, untuk yang berat curah hujan (> $15 \mathrm{~mm} /$ hari), IMERG lebih unggul dari produk lain di semua wilayah studi dan bisa digunakan di masa depan untuk model meteorologi dan hidrologi, dll. Selain itu, O (2017) juga menyatakan bahwa perkiraan curah hujan IMERG-Final memberikan hasil terbaik dengan data WEGN, diikuti oleh perkiraan IMERG-Late dan IMERGEarly, terutama untuk musim panas di Austria Tenggara. Penelitian ini bertujuan untuk menguji performa dari produk estimasi curah hujan satelit GPM di Surabaya.

\section{METODE}

Penelitian ini dilakukkan di Surabaya dengan mengambil sampel titik Stasiun Meteorologi Kelas I Juanda dengan koordinat $7.375^{\circ}$ LS $112.782^{\circ}$ BT.

Data yang digunakan yaitu data curah hujan harian bulan Januari s/d Desember 2017 pengamatan permukaan dari Stasiun Meteorologi Kelas I Juanda Surabaya yang didapat dari pusat database BMKG dan data curah hujan harian selama tahun 2017 produk satelit GPM IMERG Final Precipitation dengan resolusi spasial $0.1^{\circ} \times 0.1^{\circ}$ dan resolusi temporal 1 hari yang diunduh dari situs https://disc.gsfc.nasa.gov. Data satelit kemudian diolah menggunakan Grads dengan memasukkan koordinat terkait sehingga diketahui nilai curah hujan harian produk satelit GPM IMERG Final Precipitation di koordinat tersebut. Data tersebut kemudian diuji akurasinya dengan menggunakan metode antara lain :

1. Tabel Kontingensi (Tabel 1). Prediksi hujan dan kabut adalah contoh umum dari prakiraan ya/tidak. Untuk ambang batas hujan ditentukan yaitu curah hujan $1 \mathrm{~mm}$. Untuk memverifikasi jenis ramalan ini mulai dengan tabel kontingensi yang menunjukkan frekuensi prakiraan dan kejadian ya/tidak. (Stanski et al, 1989)

Tabel 1. Tabel kontingensi.

\begin{tabular}{llll}
\hline Obs/Satelitt & Ya & Tidak & Total \\
\hline Ya & $a$ & $c$ & total \\
\hline Tidak & $b$ & $d$ & total \\
\hline Total & total & total & $e$ \\
\hline
\end{tabular}

$$
\begin{gathered}
\text { Akurasi }=\frac{a+d}{e} \\
\text { Bias }=\frac{a+c}{a+b}
\end{gathered}
$$


2. Koefisien Korelasi (Tabel 2). Korelasi merupakan salah satu metode stastistik yang digunakan untuk mengetahui ada atau tidaknya hubungan serta arah hubungan dari dua variabel atau lebih, sedangkan koefisien korelasi (C) adalah bilangan yang menyatakan besar kecilnya suatu hubungan (Wilks, 1995)

$$
C=\frac{\sum_{i=1}^{n}\left(R O_{i}-\overline{R O}\right)\left(R E_{i}-\overline{R E}\right)}{\sqrt{\sum_{i=1}^{n}\left(R O_{i}-\overline{R O}\right)^{2}} \sqrt{\sum_{i=1}^{n}\left(R E_{i}-\overline{R E}\right)^{2}}}
$$

Tabel 2. Kategori koefisien korelasi.

\begin{tabular}{cc}
\hline Interval Koefisien & Tingkat Hubungan \\
\hline $0,00-0,199$ & Sangat Lemah \\
\hline $0,20-0,399$ & Lemah \\
\hline $0,40-0,599$ & Sedang \\
\hline $0,60-0,799$ & Kuat \\
\hline $0,80-1,000$ & Sangat Kuat \\
\hline
\end{tabular}

3. MAE (Mean Absolute Error). Mean absolute error (MAE) digunakan untuk merepresentasikan ratarata besarnya kesalahan (De Coning, 2013)

$$
M A E=\frac{\sum_{i=1}^{n}\left(R E_{i}-\overline{R O_{l}}\right)}{n}
$$

4. RMSE (Root Mean Square Error). RMSE digunakan untuk mengetahui besarnya penyimpangan yang terjadi antara prediksi total curah hujan harian dibandingkan dengan nilai total curah hujan harian aktual hasil observasi. (Sugiyono, 2004)

$$
R M S E=\sqrt{\frac{\sum_{i=1}^{n}\left(R E_{i}-\overline{R O_{l}}\right)^{2}}{n}}
$$

\section{HASIL DAN PEMBAHASAN}

Berdasarkan hasil olah data estimasi curah hujan produk satelit GPM IMERG Final Precipiattion dan data curah hujan pengamatan permukan didapatkan hasil berupa grafik curah hujan bulanan, dasarian, dan harian serta tabel nilai korelasi, akurasi, bias, RMSE, dan MAE dari curah hujan bulanan, dasarian, dan harian.

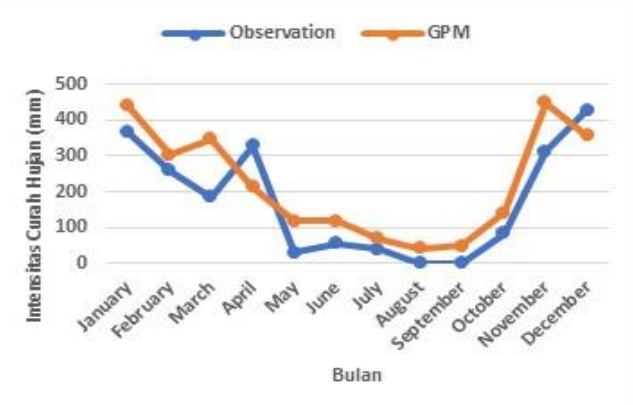

Gambar 1. Akumulasi curah hujan bulanan di Surabaya tahun 2017.
Berdasarkan Gambar 1 dapat diketahui bahwa secara umum pada tahun 2017 di Surabaya nilai akumulasi curah hujan bulanan data estimasi curah hujan produk GPM IMERG Final Pecipitation cenderung lebih tinggi terhadap akumulasi curah hujan bulanan data curah hujan pengamatan permukaan. Nilai intensitas tertinggi pada GPM terjadi pada bulan November sedangkan nilai intensitas tertinggi pada Observasi terjadi pada bulan April.

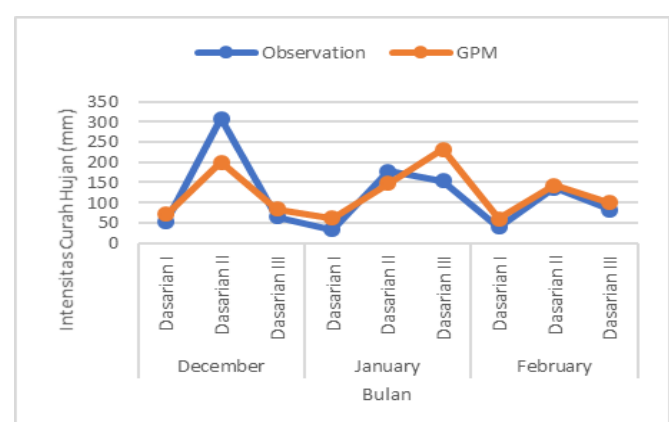

Gambar 2. Akumulasi curah hujan dasarian di Surabaya periode bulan DJF tahun 2017.

Berdasarkan Gambar 2 dapat diketahui bahwa nilai akumulasi dasarian data estimasi curah hujan produk GPM IMERG Final Precipitation periode DJF 2017 di Surabaya cenderung lebih tinggi terhadap data curah hujan akumulasi dasarian data curah hujan pengamatan permukaan kecuali pada dasarian II Bulan Desember dan dasarian II Bulan Januari. Nilai intensitas tertinggi pada GPM IMERG Final Precipitation terjadi pada bulan Januari tepatnya pada dasarian III sedangkan nilai intensitas tertinggi pada Observasi terjadi pada bulan Desember tepatnya pada dasarian II.

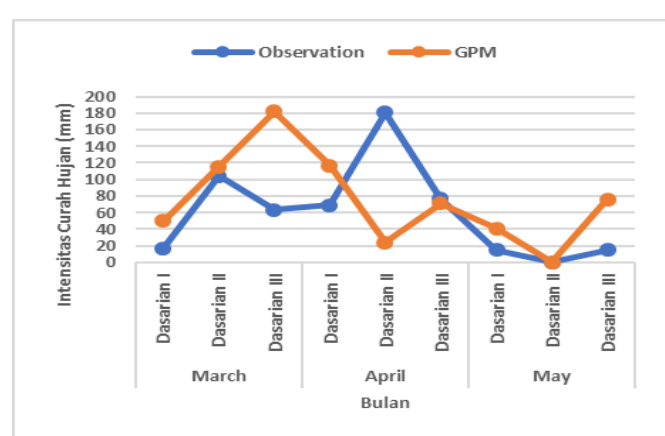

Gambar 3. Akumulasi curah hujan dasarian di Surabaya Bulan MAM tahun 2017.

Berdasarkan Gambar 3 dapat diketahui bahwa nilai akumulasi dasarian data estimasi curah hujan produk GPM IMERG Final Precipitation periode MAM 2017 di Surabaya cenderung lebih tinggi terhadap data curah hujan akumulasi dasarian data curah hujan pengamatan permukaan kecuali pada dasarian II Bulan April. Nilai intensitas tertinggi pada GPM terjadi pada bulan Maret tepatnya pada dasarian III sedangkan nilai intensitas tertinggi pada Observasi terjadi pada bulan April tepatnya pada dasarian II. 


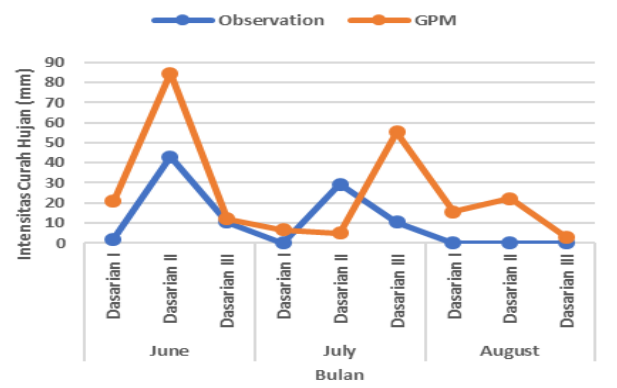

Gambar 4. Akumulasi curah hujan dasarian di Surabaya periode bulan JJA tahun 2017.

Berdasarkan Gambar 4 dapat diketahui bahwa nilai akumulasi dasarian data estimasi curah hujan produk GPM IMERG Final Precipitation periode JJA 2017 di Surabaya cenderung lebih tinggi terhadap data curah hujan akumulasi dasarian data curah hujan pengamatan permukaan kecuali pada dasarian II Bulan Juli. Nilai intensitas tertinggi pada GPM IMERG Final Precipitation terjadi pada bulan Juni tepatnya pada dasarian II sedangkan nilai intensitas tertinggi pada observasi terjadi pada bulan Juli tepatnya pada dasarian III.

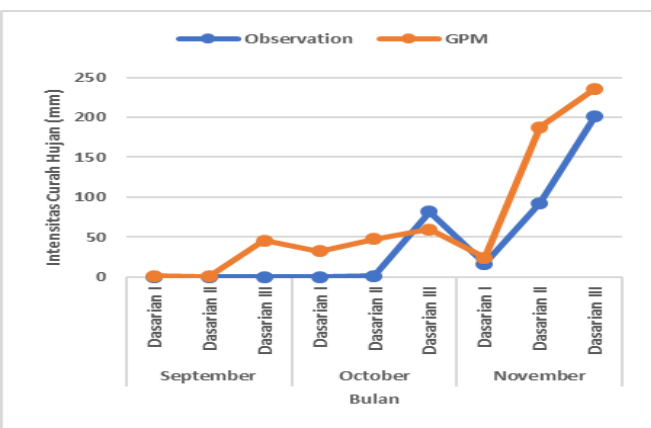

Gambar 5. Akumulasi curah hujan dasarian di Surabaya periode bulan SON tahun 2017.

Berdasarkan Gambar 5 dapat diketahui bahwa nilai akumulasi dasarian data estimasi curah hujan produk GPM IMERG Final Precipitation periode SON 2017 di Surabaya cenderung lebih tinggi terhadap data curah hujan akumulasi dasarian data curah hujan pengamatan permukaan kecuali pada dasarian III Bulan Oktober. Nilai intensitas tertinggi pada data curah hujan produk GPM IMERG Final Precipitation dan data curah hujan observasi sama-sama terjadi pada bulan November dasarian III.

Berdasarkan Gambar 6 dapat diketahui bahwa nilai akumulasi harian data estimasi curah hujan produk GPM IMERG Final Precipitation periode DJF 2017 di Surabaya cenderung memiliki intensitas yang fluktuasi terhadap data curah hujan akumulasi dasarian data curah hujan pengamatan permukaan. Akan tetapi, secara umum data curah hujan GPM IMERG Final Precipitation cukup baik dalam menentukan ada atau tidaknya hujan pada hari tersebut.

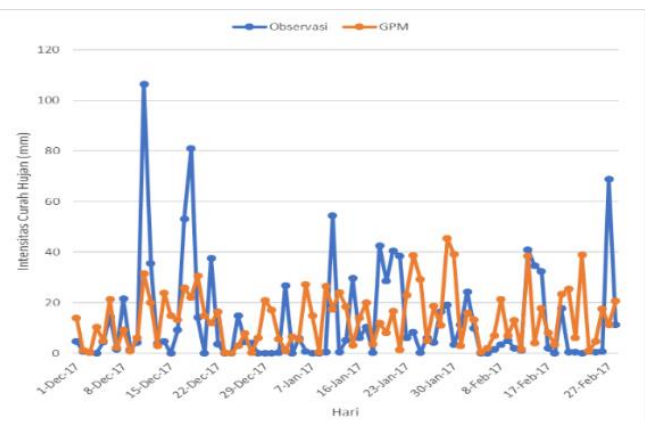

Gambar 6. Akumulasi curah hujan harian di Surabaya Bulan DJF 2017.

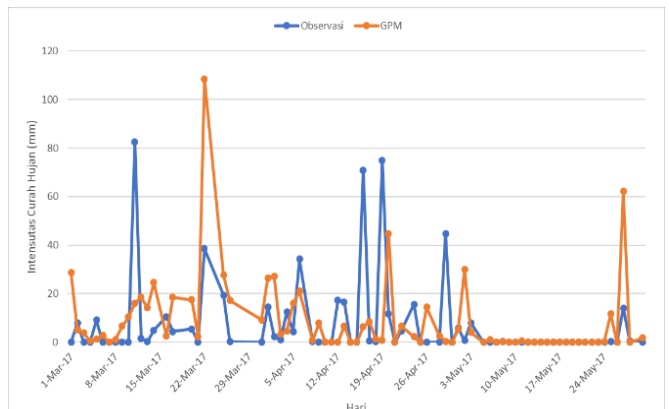

Gambar 7. Akumulasi curah hujan harian di Surabaya Bulan MAM 2017.

Berdasarkan Gambar 7 dapat diketahui bahwa nilai akumulasi harian data estimasi curah hujan produk GPM IMERG Final Precipitation periode MAM 2017 di Surabaya cenderung memiliki intensitas yang fluktuasi terhadap data curah hujan akumulasi dasarian data curah hujan pengamatan permukaan. Pada beberapa tanggal akumulasi harian dari data GPM IMERG Final Precipitation lebih tinggi. Oleh karena itu, korelasi fluktuasi harian antara data GPM dan data observasi cenderung bervariasi. Akan tetapi, secara umum data curah hujan GPM IMERG Final Precipitation cukup baik dalam menentukan ada atau tidaknya hujan pada hari tersebut.

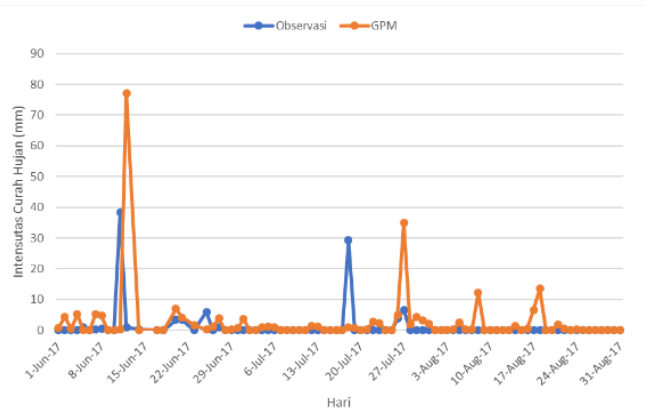

Gambar 8. Akumulasi curah hujan harian di Surabaya Bulan JJA 2017.

Berdasarkan Gambar 8 dapat diketahui bahwa nilai akumulasi harian data estimasi curah hujan produk GPM IMERG Final Precipitation periode JJA 2017 di Surabaya cenderung memiliki intensitas yang homogen terhadap data curah hujan akumulasi dasarian data curah hujan pengamatan permukaan. Hampir rata-rata nilai 
curah hujan bernilai nol. Pada beberapa tanggal perbedaan fluktuasi antara data GPM dan data observasi terjadi sangat signifikan. Akan tetapi, secara umum data curah hujan GPM IMERG Final Precipitation cukup baik dalam menentukan ada atau tidaknya hujan pada hari tersebut.

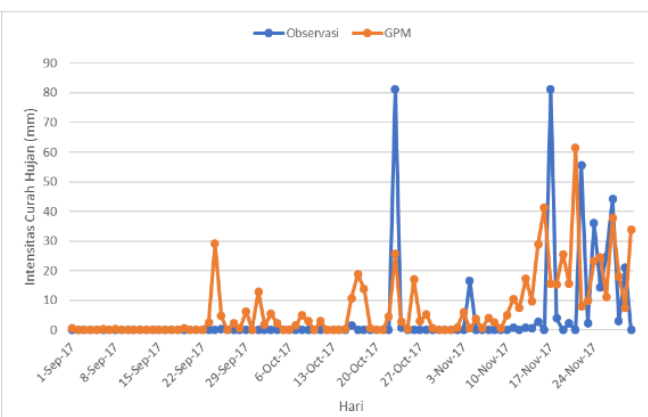

Gambar 9. Akumulasi curah hujan harian di Surabaya Bulan SON 2017.

Berdasarkan Gambar 9 dapat diketahui bahwa nilai akumulasi harian data estimasi curah hujan produk GPM IMERG Final Precipitation periode SON 2017 di Surabaya cenderung memiliki intensitas yang homogen terhadap data curah hujan akumulasi dasarian data curah hujan pengamatan permukaan. Hampir rata-rata nilai curah hujan bernilai nol. Pada beberapa tanggal perbedaan fluktuasi antara data GPM dan data observasi terjadi sangat signifikan. Akan tetapi, secara umum data curah hujan GPM IMERG Final Precipitation cukup baik dalam menentukan ada atau tidaknya hujan pada hari tersebut.

Berdasarkan Tabel 3 dapat diketahui bahwa nilai korelasi untuk akumulasi curah hujan bulanan antara data estimasi produk satelit GPM IMERG Final Precipitation dengan data curah hujan permukaan memiliki nilai yang sangat baik yaitu 0.88. Akan tetapi memiliki nilai error yang cukup tinggi ditunjukkan dengan nilai RMSE dan MAE yang besar.

Berdasarkan Tabel 4 dapat diketahui bahwa nilai korelasi untuk akumulasi curah hujan dasarian antara data estimasi produk satelit GPM IMERG Final Precipitation dengan data curah hujan permukaan memiliki nilai yang sangat baik pada saat musim hujan dan kemarau. Sedangkan pada saat periode transisi dari musim hujan ke musim kemarau atau sebaliknya memiliki korelasi yang rendah.

Berdasarkan Tabel 5 dapat diketahui bahwa nilai korelasi untuk akumulasi curah hujan harian antara data estimasi produk satelit GPM IMERG Final Precipitation dengan data curah hujan permukaan secara umum memiliki nilai korelasi yang rendah, tetapi memiliki nilai akurasi yang cukup tinggi (Tabel 6). Nilai akurasi tersebut digunakan untuk mendefinisikan ada atau tidaknya hujan. Sedangkan, untuk nilai error akumulasi curah hujan harian cukup tinggi dengan nilai RMSE yang cukup tinggi. Nilai MAE secara umum cukup kecil yang menandakan besarnya nilai error rata-rata antara data curah hujan produk satelit GPM IMERG Final Precipitation dengan data curah hujan pengamatan permukaan.

Tabel 3. Akumulasi curah hujan bulanan di Surabaya 2017.

Akumulasi curah hujan bulanan

\begin{tabular}{ccc}
\hline Korelasi & RMSE & MAE \\
\hline 0.877561462 & 86.73938718 & 46.33454 \\
\hline
\end{tabular}

Tabel 4. Akumulasi curah hujan dasarian di Surabaya 2017.

Akumulasi curah hujan dasarian

\begin{tabular}{ccccc}
\hline & & Korelasi & RMSE & MAE \\
\hline $\begin{array}{c}\text { Musim } \\
\text { hujan }\end{array}$ & DJF & 0.83 & 47.93 & 5.25 \\
\hline $\begin{array}{c}\text { Musim } \\
\text { kemarau }\end{array}$ & JJA & 0.63 & 24.67 & 14.46 \\
\hline $\begin{array}{c}\text { Periode } \\
\text { transisi } \\
\text { (hujan ke }\end{array}$ & MAM & 0.13 & 71.81 & 15.03 \\
kemarau) & & & & \\
\hline $\begin{array}{c}\text { Periode } \\
\text { transisi } \\
\text { kemarau } \\
\text { ke hujan) }\end{array}$ & SON & 0.32 & 15.52 & 26.81 \\
\hline
\end{tabular}

Tabel 5. Akumulasi curah hujan harian di Surabaya 2017.

\begin{tabular}{|c|c|c|c|c|}
\hline \multicolumn{5}{|c|}{ Akumulasi curah hujan harian } \\
\hline & & Korelasi & RMSE & MAE \\
\hline $\begin{array}{l}\text { Musim } \\
\text { Hujan }\end{array}$ & DJF & 0.23 & 20.50 & 0.58 \\
\hline $\begin{array}{c}\text { Musim } \\
\text { Kemarau }\end{array}$ & JJA & 0.04 & 10.49 & 10.49 \\
\hline $\begin{array}{c}\text { Periode } \\
\text { transisi } \\
\text { (hujan ke } \\
\text { kemarau) }\end{array}$ & MAM & 0.26 & 19.65 & 1.51 \\
\hline $\begin{array}{l}\text { Periode } \\
\text { Transisi } \\
\text { (kemarau } \\
\text { ke hujan) }\end{array}$ & SON & 0.32 & 15.52 & 2.65 \\
\hline
\end{tabular}

Tabel 6. Tabel kontingensi curah hujan harian di Surabaya tahun 2017.

\begin{tabular}{|c|c|c|c|}
\hline \multicolumn{4}{|c|}{ Akumulasi curah hujan harian } \\
\hline & & Akurasi & Bias \\
\hline $\begin{array}{l}\text { Musim } \\
\text { Hujan }\end{array}$ & DJF & 0.81 & 1.07 \\
\hline $\begin{array}{c}\text { Musim } \\
\text { Kemarau }\end{array}$ & JJA & 0.71 & 2.07 \\
\hline $\begin{array}{c}\text { Periode } \\
\text { transisi } \\
\text { (hujan ke } \\
\text { kemarau) }\end{array}$ & MAM & 0.74 & 1.16 \\
\hline $\begin{array}{l}\text { Periode } \\
\text { Transisi } \\
\text { (kemarau } \\
\text { ke hujan) }\end{array}$ & SON & 0.67 & 2.33 \\
\hline
\end{tabular}




\section{KESIMPULAN}

Berbeda dengan satelit lain, seperti TRMM, GPM-IMERG menggunakan sensor untuk mendeteksi hujan ringan maupun hujan deras dan salju. Tiga perbaikan penting dalam GPM adalah bahwa (1) kemiringan orbital telah ditingkatkan dari $35^{\circ}$ menjadi $65^{\circ}$ sehingga memberikan tambahan cakupan zona iklim; (2) radar telah ditingkatkan ke dua frekuensi, menambah kepekaan terhadap hujan ringan; dan (3) saluran frekuensi tinggi $(165,5$ dan $183,3 \mathrm{GHz}$ ) telah ditambahkan ke imager gelombang mikro pasif (PMW), yang diharapkan dapat memfasilitasi penginderaan hujan ringan dan padat (Sharifi, 2016).

Dalam penelitian ini dapat disimpulkan bahwa secara umum estimasi data curah hujan produk GPM IMERG Final Precipitation dengan data curah hujan pengamatan permukaan di Surabaya memiliki korelasi yang sangat baik untuk memperkirakan akumulasi curah hujan bulanan. Sedangkan, untuk akumulasi harian, secara umum estimasi curah hujan produk GPM IMERG Final Precipitation memiliki korelasi yang sangat rendah. Sementara itu untuk akumulasi sepuluh harian, data curah hujan produk satelit GPM IMERG Final Precipitation memiliki korelasi yang baik terutama di periode DJF (Desember, Januari, Februari) dan JJA (Juni, Juli, Agustus), akan tetapi memiliki korelasi yang rendah selama periode transisi dari musim hujan ke musim kemarau atau sebaliknya yaitu MAM (Maret, April, Mei) dan SON (September, Oktober, November). Pada umumnya, produk ini sangat bagus dalam menentukan ada atau tidaknya hujan, tetapi performa sangat rendah dalam menentukan besarnya intensitas curah hujan untuk data curah hujan harian dan memiliki nilai korelasi yang rendah di semua musim. Sementara itu, secara keseluruhan kinerja data estimasi curah hujan produk GPM IMERG Final Precipitation cenderung oversetimate dengan nilai MAE dan RMSE yang tinggi.

\section{DAFTAR PUSTAKA}

De Coning, E. (2013). Optimizing Satellite-based Precipitation Estimation for Nowcasting of Rainfall and Flash Flood Events over the South African Domain. Remote Sensing, 5(11), 5702-5724. doi: 10.3390/rs5115702

Hou, A.Y., Kakar, R.K., Neeck, S., Azarbarzin, A.A., Kummerow, C.D., Kojima, M., Oki, R., Nakamura, K., Iguchi, T. (2014). The Global Precipitation Measurement Mission. Bulletin of the American Meteorological Society, 95(5), 701-722. doi: 10.1175/BAMS-D-13-00164.1
Huffman, G.J., Bolvin, D.T., Braithwaite, D., Hsu, K., Joyce, R., Kidd, C., Nelkin, E.J., Xie, P. (2015). Algorithm Theoretical Basis Document (ATBD) Version 4.5: NASA Global Precipitation Measurement (GPM) Integrated Multi-satellite Retrievals for GPM (IMERG). NASA: Greenbelt, MD, USA.

Kidd, C., Huffman, G. (2011). Global Precipitation Measurement. Meteorological Applications, 18(3), 334-353. doi: 10.1002/met.284

Kidd, C., Kniveton, D.R., Todd, M.C., Bellerby, T.J. (2003). Satellite Rainfall Estimation Using Combined Passive Microwave and Infrared Algorithms. Journal of Hydrometeorology, 4(6), 1088-1104. doi: 10.1175/15257541(2003)004<1088:SREUCP>2.0.CO;2

Kidd, C., Levizzani, V. (2011). Status of Satellite Precipitation Retrievals. Hydrology and Earth System Sciences, 15(4), 1109-1116. doi: 10.5194/hess-15-1109-2011

O, S., Foelsche, U., Kirchengast, G., Fuchsberger, J., Tan, J., Petersen, W.A. (2017). Evaluation of GPM IMERG Early, Late and Final Rainfall Estimates Using WegenerNet Gauge Data in Southeastern Austria. Hydrology and Earth System Sciences, 21(12), 6559-6572. doi: 10.5194/hess-216559-2017

Sharifi, E., Steinacker, R., Saghafian, B. (2016). Assessment of GPM-IMERG and Other Precipitation Products against Gauge Data under Different Topographic and Climatic Conditions in Iran: Preliminary Results. Remote Sensing, 8(2), $135 . \quad$ doi: 10.3390/rs8020135

Stanski, H.R., Wilson, L.J., Burrows W.R. (1989). Survey of Common Verification Methods in Meteorology. WMO World Weather Watch Technical Report No.8, WMO/TD No.358.

Sugiyono. (2004). Statistik Untuk Penelitian. Bandung: Alfa Beta.

Tapiador, F.J., Turk, F.J., Petersen, W., Hou, A.Y., García-Ortega, E., Machado, L.A.T., Angelis, C.F., Salio, P., Kidd, C., Huffman, G.J., de Castro, M. (2012). Global Precipitation Measurement: Methods, Datasets and Applications. Atmospheric Reseach, 104-105, 70-97. doi: 10.1016/j.atmosres.2011.10.021

Wilks, D.S. (1995). Statistical Method in the Atmospheric Sciences. San Diego: Academic Press Inc.

Yong, B., Liu, D., Gourley, J.J., Tian, Y., Huffman, G.J., Ren, L., Hong, Y. (2015). Global View of Real-time TRMM Multisatellite Precipitation Analysis: Implications for Its Successor Global Precipitation Measurement Mission. Bulletin of the American Meteorological Society, 96(2), 283-296. doi: 10.1175/BAMS-D-1400017.1 